\section{Palliative care}

\section{SELF-ASSESSMENT QUESTIONNAIRE}

\section{SAQs - and answers - are ONLINE for RCP Fellows and Collegiate Members}

The SAQs printed in the CME section can be answered online to achieve External CPD credits.

\section{The answering process}

1. To access the questions, log on to the Fellows and Members area http://www.rcplondon.ac.uk/Members/SAQ (those who have not yet registered will be automatically directed to the registration pages)

2. Select: Online learning $S A Q$

3. At the top of the SAQ page select the current CME question paper

4. Answer all 10 questions in any order, by indicating true or false

5. Check your answers and change them if you wish to

6. Click on Submit for final marking.

(Note - after submitting your answers NO changes are possible)

\section{The marking process}

- You must submit the answers before the closing date shown at the top of the screen

- Answers will be marked automatically on the date displayed for that paper

- You can find your marks with explanations of the answers on the CME page under My past CME papers

\section{Registering your External CPD credits}

A pass mark of $80 \%$ allows you to claim 2 External CPD credits. Thus by answering the SAQs in each issue of Clinical Medicine you can achieve 12 external credits in one year.

To claim your credits:

- Online registrants: You can record your credits using the online diary system. All Clinical Medicine SAQs are listed under External Approved CPD

- Manual registrants: You can record your credits using your paper diary sheets. Manual registrants are required to keep evidence of their participation in the SAQ and the score attained.

Please note that past papers will be stored for 12 months.

For those who wish to submit their answers on paper, please see guidance at the end of these SAQs.
1 A 63-year-old man with advanced lung cancer presented with waking at night feeling breathless and panicky. He was breathless on moderate exertion during the day. Which of the following statements are true and which false?

(a) An antidepressant may be helpful

(b) An opioid is unlikely to help his nocturnal symptoms

(c) Occupational therapy would play no role in managing his breathlessness

(d) Acupuncture should be considered for his breathlessness

(e) Lorazepam as required is likely to be useful

2 A 54-year-old woman with breast cancer, liver and bone metastases presented with increasing breathlessness and chest pain. Chest

$\mathrm{X}$-ray showed a moderate sized left-sided pleural effusion. A computed tomography (CT) pulmonary angiogram confirmed a large pulmonary embolus. She was very frail and no further chemotherapy was possible. Her bone marrow was suppressed. She was taking MST continus $40 \mathrm{mg}$ bd for bony pain. Which of the following statements are true and which false?

(a) Pleurodesis is unlikely to be useful

(b) She should be given warfarin to prevent further pulmonary embolism

(c) Her MST continus should be increased to $80 \mathrm{mg}$ bd to help her breathlessness

(d) When lying in bed, she is likely to benefit most from lying on her left side

(e) Nebulised opioids are likely to be of significant benefit

3 A 63-year-old man was admitted to hospital complaining of sudden abdominal distension and a six-month history of bloody stools, poor appetite and fatigue. He had lost $7 \%$ of his pre-illness stable weight. On examination, his body mass index was 23 and there was a firm craggy mass in the right upper quadrant of the abdomen. Blood tests revealed haemoglobin $(\mathrm{Hb}) 63 \mathrm{~g} / \mathrm{l}$ and albumin $19 \mathrm{~g} / \mathrm{l}$. Abdominal X-ray demonstrated a dilated colon. On colonoscopy, an obstructive sigmoid tumour was found. CT scan confirmed metastatic tumour deposits in the liver. Which of the following statements are true and which false? 
(a) He should have an intervention to relieve the obstruction of his bowel

(b) He should immediately be treated with total parenteral nutrition

(c) If he is still anaemic when the rectal bleeding has been treated he should be treated with erythropoietin

(d) Combined treatment with fish oil capsules and high protein/calorie supplements would be a reasonable approach to his weight loss and fatigue

(e) He should take all available opportunity to rest

4 A 62-year-old man presented with a six-month history of progressive dysphagia, but he otherwise felt well. On examination, he was thin and clearly cachectic and there was peripheral oedema.

Investigation with a CT scan and upper-gastrointestinal endoscopy revealed an advanced metastatic oesophageal carcinoma. Which of the following statements are true and which false?

(a) As he feels well, the involvement of the multidisciplinary team in his care is unnecessary

(b) Every effort should be made to restore his food intake, including oesophageal stenting or laser canalisation of the tumour

(c) Medroxyprogesterone might improve his appetite but would not produce a gain in lean body mass

(d) He will inevitably have a low metabolic rate.

(e) If he is taking an angiotensin-converting enzyme inhibitor this should be stopped when the diagnosis of cancer cachexia is established

5 A 73-year-old retired coal miner was found to have small cell lung cancer, presenting with neuropathic pain in his right arm from a mass in the apex of the right lung. The pain had responded to amitriptyline $25 \mathrm{mg}$ daily and chemotherapy had been commenced. On day 18 of his first cycle of chemotherapy with cisplatinum, mitomycin-C and vinblastine (all given on day 1 of each 21-day cycle) he returned to the clinic complaining of abdominal discomfort, hiccups and vomiting for the previous week. He had no appetite and very little nausea. He had been given intravenous (iv) ondansetron on the morning of his chemotherapy and then took oral ondansetron for the following 48 hours. He reported that he felt nauseated for a day or two after his chemotherapy but vomited very little. On examination, he was apyrexial, thin, there was finger clubbing, a mild right ptosis and some wasting of the small muscles of the right hand. His chest was clear. There was epigastric tenderness and a sucussion splash. Investigations showed $\mathrm{Hb} 12.9 \mathrm{~g} / \mathrm{dl}$, white blood cell count (WBC) $3.1 \times 10^{9} /$, sodium $(\mathrm{Na})$ $139 \mathrm{mmol} / \mathrm{l}$, calcium (total) $2.54 \mathrm{mmol} / \mathrm{l}$, potassium (K) $4.2 \mathrm{mmol} / \mathrm{l}$, albumin $37 \mathrm{~g} / \mathrm{l}$, urea $8.6 \mathrm{mmol} / \mathrm{l}$, protein $65 \mathrm{~g} / \mathrm{l}$ and creatinine $112 \mathrm{~mol} / \mathrm{l}$. Which of the following statements are true and which false?

(a) He should be given a further 48 hours of ondansetron

(b) His symptoms are most likely to be caused by liver metastases

(c) His symptoms would respond to a prokinetic agent

(d) These symptoms could be caused by his analgesic therapy

(e) Hypercalcaemia would cause these symptoms

6 A 42-year-old secretary was known to have peritoneal metastases from relapsed ovarian carcinoma, for which she had previously received two courses of chemotherapy. She had declined any further chemotherapy and wished to maximise her quality of life with her two small children. She complained of recurrent episodes of colicky central abdominal pain, nausea and vomiting. She was admitted to a medical ward at the request of her general practitioner because of intractable nausea and vomiting over the previous 72 hours. She had not passed faeces or flatus per rectum for at least 36 hours. On examination, she was thin, pale and dehydrated. Her abdomen was soft and multiple craggy masses were palpable. An abdominal X-ray showed multiple dilated loops of large and small bowel with fluid levels. Investigations showed Hb $9.9 \mathrm{~g} / \mathrm{dl}$, WBC $5.6 \times 10^{9} / \mathrm{l}$, $\mathrm{Na} 146 \mathrm{mmol} / \mathrm{l}, \mathrm{K} 4.8 \mathrm{mmol} / \mathrm{I}$, urea $15.3 \mathrm{mmol} / \mathrm{l}$, creatinine $118 \mathrm{~mol} / \mathrm{l}$. Which of the following statements are true and which false?

(a) Oral cyclizine $50 \mathrm{mg}$ tds is an appropriate anti-emetic regimen

(b) iv rehydration is contraindicated

(c) Surgery is unlikely to be of benefit

(d) Intestinal stretch is likely to be stimulating her vomiting centre

(e) If vomit volumes are large, octreotide may help to reduce them

7 A 35-year-old man who had been treated for metastatic colonic cancer continued to complain of abdominal pain for which the usual investigations revealed no apparent cause. He had a past history of substance abuse but said this was caused by a relationship he terminated several months prior to this admission. It was suspected he was self-medicating with substances brought into the ward by a friend but he denied this. There were signs that he was becoming opioid toxic but his complaints of pain increased. The tactful suggestion of referral for a psychiatric or psychological opinion was angrily rebuffed with accusations that no one was taking his pain seriously. Which of the following statements are true and which false?

(a) There should be ongoing assessment for physical causes for the pain 
(b) Non-pharmacological strategies for pain management are likely to be ineffective

(c) Only direct patient contact with a mental health professional will help in this situation

(d) Cancer pain and chronic pain are mutually exclusive

(e) There should be consultation with the addiction and palliative care services to negotiate a treatment plan with the patient

8 A widower in his early 70s with metastatic lung cancer was admitted for pain and symptom control. He had a previous history of intermittent alcohol abuse but reported abstinence since admission three weeks previously. He was quiet and uncomplaining during the day but the nursing staff reported that they found him tearful at night because of 'bad dreams'. He was reluctant to discuss the content of these dreams during the day. He was due to be discharged home. Which of the following statements are true and which false?

(a) Changing his medication would stop the dreams

(b) He should be assessed and treated for depression

(c) He probably becomes confused and has hypnagogic hallucinations at night because of hypoxia

(d) He might be experiencing alcohol withdrawal symptoms

(e) $\mathrm{He}$ is a high suicide risk

9 A 60-year-old man with locally advanced colorectal cancer in the pelvis presented with a constant, dull sacral pain and a severe, spontaneous, sharp, shooting pain in an L2-S1 distribution, worse on the right side. Co-codamol strong (30/500) two tablets six-hourly was prescribed. Each dose helped the dull sacral pain for $30 \mathrm{~min}$. Which of the following statements are true and which false?

(a) His pain has nociceptive and neuropathic components

(b) A switch to another codeine containing preparation may be beneficial

(c) An opioid for severe pain such as morphine should be prescribed

(d) $\mathrm{He}$ is unlikely to need an adjuvant analgesic

(e) His pain will not respond to opioid analgesics

10 A 50-year-old man with inoperable lung cancer and liver metastases presented with pleuritic chest pain and painful hepatomegaly. He had persistent nausea, a poor appetite and felt unable to take his oral morphine. Which of the following statements are true and which false?

(a) His symptoms are likely to be interrelated

(b) Painful hepatomegaly may be controlled by steroids

(c) A change in route of delivery of the opioid will not help in this situation

(d) He will not benefit from an increase in opioid dose

(e) A nerve block is indicated at this point

\section{Guidelines on completing the answer sheet for those who wish to submit their answers on paper}

A loose leaf answer sheet is enclosed, which will be marked electronically at the Royal College of Physicians. Answer sheets must be returned by 21 May 2006 to: CME Department (SAQs), Royal College of Physicians, 11 St Andrews Place, London NW1 4LE.

Overseas members only can fax their answers to 02074874156

Correct answers will be published in the next issue of Clinical Medicine.

Further details on CME are available from the CME Department at the Royal College of Physicians (address above or telephone 02079351174 extension 306 or 309).

Your completed answer sheet will be scanned to enable a quick and accurate analysis of results. To aid this process, please keep the following in mind:

1 Please print your GMC Number firmly and neatly

2 Only write in allocated areas on the form

3 Only use pens with black or dark blue ink

4 For optimum accuracy, ensure printed numbers avoid contact with box edges

5 Please shade circles like this: Not like this: $\varnothing$

6 Please mark any mistakes made like this:

7 Please do not mark any of the black squares on the corners of each page

8 Please fill in your full name and address on the back of the answer sheet in the space provided; this will be used to mail the form back to you after marking.

\section{CME Liver Disease SAQs}

\section{Answers to the CME SAQs published in} Clinical Medicine January/February 2006

$\begin{array}{llllllllll}\text { Q1 } & \text { Q2 } & \text { Q3 } & \text { Q4 } & \text { Q5 } & \text { Q6 } & \text { Q7 } & \text { Q8 } & \text { Q9 } & \text { Q10 } \\ \text { a) } F & \text { a) } T & \text { a) } T & \text { a) } F & \text { a) } T & \text { a) } T & \text { a) } T & \text { a) } F & \text { a) } T & \text { a) } F \\ \text { b) } F & \text { b) } T & \text { b) } T & \text { b) } F & \text { b) } F & \text { b) } F & \text { b) } F & \text { b) } F & \text { b) } F & \text { b) } T \\ \text { c) } F & \text { c) } F & \text { c) } F & \text { c) } T & \text { c) } F & \text { c) } T & \text { c) } T & \text { c) } F & \text { c) } T & \text { c) } F \\ \text { d) } T & \text { d) } F & \text { d) } T & \text { d) } T & \text { d) } F & \text { d) } F & \text { d) } F & \text { d) } T & \text { d) } F & \text { d) } T \\ \text { e) } T & \text { e) } F & \text { e) } T & \text { e) } F & \text { e) } F & \text { e) } T & \text { e) } F & \text { e) } T & \text { e) } T & \text { e) } F\end{array}$

